\title{
Microstructural and Mechanical Characteristics of Novel 6\% Cr Cold-Work Tool Steel
}

\author{
Singon Kang ${ }^{1}$, Minwook Kim ${ }^{2}$ and Seok-Jae Lee ${ }^{2, *}$ \\ 1 Advanced Steel Processing and Products Research Center, Department of Metallurgical and Materials \\ Engineering, Colorado School of Mines, Golden, CO 80401, USA; sikang@mines.edu \\ 2 Division of Advanced Materials Engineering, Research Center for Advanced Materials Development, \\ Chonbuk National University, Jeonju 561-756, Korea; kmw0717@jbnu.ac.kr \\ * Correspondence: seokjaelee@jbnu.ac.kr; Tel.: +82-63-270-2298
}

Academic Editor: Klaus-Dieter Liss

Received: 8 September 2016; Accepted: 3 January 2017; Published: 6 January 2017

\begin{abstract}
We investigated a new cold-work tool steel with a low $\mathrm{Cr}$ content of 6 wt. \% which was designed based on thermodynamic calculation to minimize the formation of primary carbide. A smaller particle size and a smaller volume fraction of carbides were observed in this 6\% $\mathrm{Cr}$ steel. Superior mechanical properties in terms of hardness, impact toughness, tensile strength, and total elongation were achieved in this steel, due to fine secondary carbides precipitated during tempering. These carbide particles were $\mathrm{M}_{6} \mathrm{C}$ and $(\mathrm{Mo}, \mathrm{V}) \mathrm{C}$ carbides with a diameter below $100 \mathrm{~nm}$.
\end{abstract}

Keywords: cold-work tool steel; alloy design; carbide formation; tempering

\section{Introduction}

The recent trend in the automotive industry is to enhance the use of advanced high-strength steel (AHSS), which reduces the weight of vehicles and improves fuel efficiency. Simultaneously, the use of high-strength tool steels is required for various metal working processes, e.g., press forming or drawing. For an effective metal working process, basically, the strength of tool steels should be higher than that of AHSS which is fabricated using the tool steels. This means that the development of tool steels tends to take precedence over the development of AHSS as there is a huge demand for AHSS with a strength higher than $1 \mathrm{GPa}$.

The tool steels mainly consist of high $\mathrm{C}$, high $\mathrm{Cr}$, and other carbide-forming elements such as Mo, V, and W [1-3]. The mechanical properties of the tool steels can be influenced by altering the tempering condition, which is related to the type and amount of carbides formed during tempering. For instance, a tempered STD11 steel, widely used as a representative of cold-work tool steel, has a high hardness over $58 \mathrm{HRC}$ and a good wear resistance due its high carbide content in the tempered martensite matrix. However, some transition carbides can act as crack initiation sites, which lower the toughness of the product $[4,5]$. It has been reported that the primary carbide formed and coarsened can be elongated during hot deformation, which causes vacancy formation and crack initiation due to the anisotropy of the elongated shape of the carbide [6].

Recently, the development trend of the cold-work tool steels is to reduce the amounts of $\mathrm{C}$ and $\mathrm{Cr}$, to decrease the volume fraction and size of the primary carbides [7-11]. These steels with a lower $\mathrm{Cr}$ content have better mechanical properties, because the formation of primary carbide is suppressed, compared to STD11 steel. Kim et al. developed a cold-work tool steel containing $8 \mathrm{wt}$ \% \% Cr, which was designed based on thermodynamic calculations to avoid the primary carbide [11]. However, they observed some amounts of primary carbide in the proposed $8 \% \mathrm{Cr}$ steel specimen.

Therefore, in the present work, we developed a new cold-work tool steel with a Cr content of 6 wt. \%. The reduced $\mathrm{Cr}$ content was designed to inhibit the formation of the primary carbide as much 
as possible. The expected strength decrease due to the reduction of $\mathrm{Cr}$ content was complemented by increasing the amounts of carbide-forming elements, such as Mo, V, and W. The mechanical properties and microstructural features of the developed $6 \% \mathrm{Cr}$ cold-work steel were evaluated in comparison with those of STD11 steel after a conventional quenching and tempering treatment.

\section{Materials and Methods}

The chemical composition of the steels used in this study is shown in Table 1. The base contents of $\mathrm{C}$ and $\mathrm{Cr}$ in the newly designed steel alloy were $0.9 \mathrm{wt} . \%$ and $6.0 \mathrm{wt}$. \%, respectively (hereinafter referred to as "Cr6C9" steel). The commercial STD11 steel was used to evaluate the Cr6C9 steel. Then $30 \mathrm{~kg}$ of the Cr6C9 steel ingot was fabricated by vacuum induction melting (VIM). The ingot was homogenized at $1150{ }^{\circ} \mathrm{C}$ for $1 \mathrm{~h}$ and hot-forged to remove the cast structure. The forged plate was annealed at $870{ }^{\circ} \mathrm{C}$ for $4 \mathrm{~h}$, followed by furnace cooling for spheroidization. Charpy U-notched specimens and ASTM E8 sub-size tensile specimens with the gauge length of $25.4 \mathrm{~mm}$ and the thickness of $1.5 \mathrm{~mm}$ were prepared from the spheroidized plate. The machined specimens were austenitized at $1030{ }^{\circ} \mathrm{C}$ for $30 \mathrm{~min}$ in a vacuum tube furnace under the vacuum condition and then air-cooled to room temperature. The tempering treatment was carried out at $520^{\circ} \mathrm{C}$ for $2 \mathrm{~h}$ twice, indicating $4 \mathrm{~h}$ tempering in total. The microstructure of the tempered specimens was observed under an optical microscope (OM, Leica Co., DM ILM, Wetzlar, Germany) and a field emission emitter scanning electron microscope (FE-SEM, Hitachi Co., SU-70, Tokyo, Japan). The samples were mechanically polished to $1 \mu \mathrm{m}$ and etched in the Vilella etchant $(0.6 \mathrm{~g}$ picric acid $+3 \mathrm{~mL} \mathrm{HCl}+97 \mathrm{~mL}$ ethanol). Carbon replica samples were prepared to observe small carbides below $500 \mathrm{~nm}$ in diameter by means of a transmission electron microscope (TEM, JEM-2010, JEOL, Ltd, Tokyo, Japan) with an energy dispersive spectrometer (EDS). The volume fraction of retained austenite was determined using X-ray diffraction (XRD, RIGAKU MAX-2500, Rigaku Co., Tokyo, Japan) with $\mathrm{Cu} \mathrm{K} \alpha$ radiation. The equation to calculate the volume fraction of retained austenite is mentioned in detail in reference [10]. Room temperature tensile test was carried out with a strain rate of $1 \times 10^{-3} \mathrm{~s}^{-1}$ using Instron 5982 testing machine (Instron, Norwood, MA, USA). The hardness of the tempered specimens was measured on the Rockwell hardness $C$ scale. The Charpy U-notch impact test was carried out to evaluate the impact toughness.

Table 1. Chemical composition of two steels used in the present study in wt. \%.

\begin{tabular}{ccccccccc}
\hline Steels & C & Si & Mn & Cr & Mo & W & V & Fe \\
\hline Cr6C9 & 0.88 & 0.56 & 0.56 & 6.08 & 3.27 & 0.52 & 0.99 & Bal. \\
STD11 & 1.48 & 0.23 & 0.26 & 11.17 & 0.74 & - & 0.23 & Bal. \\
\hline
\end{tabular}

\section{Results and Discussion}

Figure 1 shows the temperature-dependent equilibrium phase volume fractions for the Cr6C9 and STD11 steels determined by means of the MatCalc software [12]. The database of "mc_fe_v2.057.tdb" is used for the thermodynamic calculations in MatCalc. The solidification temperature and the initial temperature required to form the primary carbide were compared. In the STD11 steel, the solidification temperature was $1248^{\circ} \mathrm{C}$, but the primary $\mathrm{M}_{7} \mathrm{C}_{3}$ carbide appeared at the higher temperature of $1252^{\circ} \mathrm{C}$. It indicates that the $\mathrm{M}_{7} \mathrm{C}_{3}$ carbide can be precipitated before the full solidification and the precipitates easily coarsened during the following thermo-mechanical processing, which had a damaging influence on the mechanical properties. The solidification in the Cr6C9 steel was completed at $1244{ }^{\circ} \mathrm{C}$, similar to the STD11 steel. As the temperature decreased, $\mathrm{M}_{6} \mathrm{C}$ carbide was precipitated at $1196{ }^{\circ} \mathrm{C}$ and $\mathrm{M}_{7} \mathrm{C}_{3}$ carbide was precipitated at $1110{ }^{\circ} \mathrm{C}$, successively. The carbide precipitation appeared at a temperature lower than the solidification temperature in the $\mathrm{Cr} 6 \mathrm{C} 9$ steel. It is presumed that this temperature gap effectively suppressed the formation of the primary carbide, which appeared during solidification. The main alloy design concept of the Cr6C9 steel was to lower the carbide initiation temperature below 
the solidification temperature as much as possible in order to minimize the actual volume fraction and size of the primary carbide after quenching and tempering.

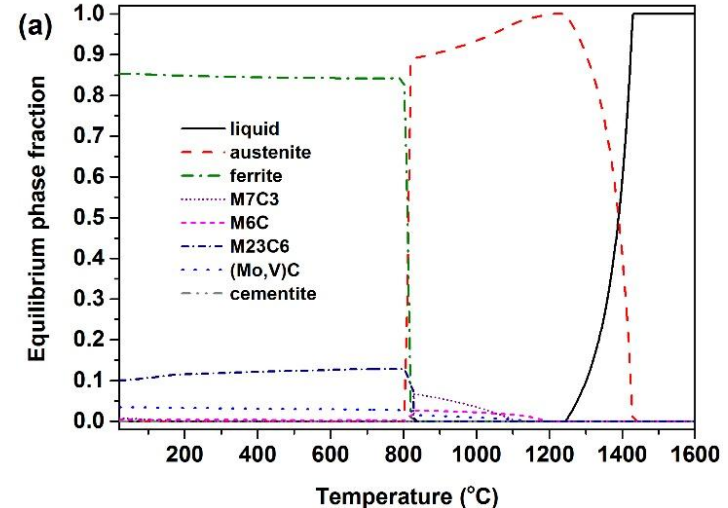

(a)

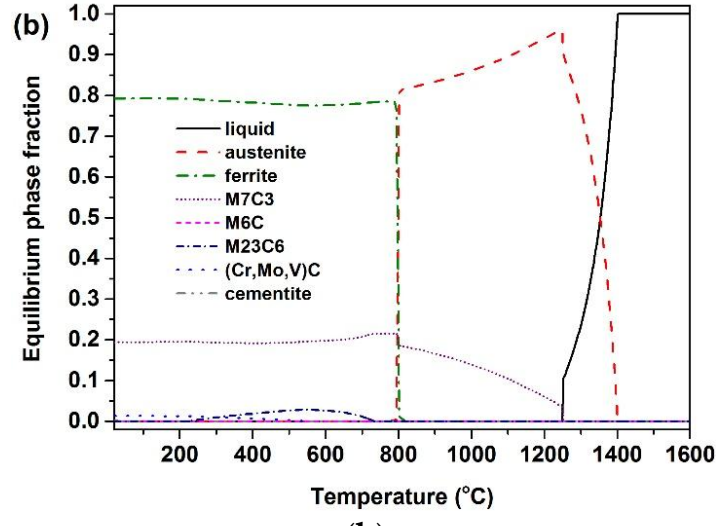

(b)

Figure 1. Equilibrium phase fractions calculated by using MatCalc (ver. 5.62) for the two steels: (a) Cr6C9 and (b) STD11.

Figure 2 shows the optical micrographs of the tempered Cr6C9 and STD11 specimens. The carbides in white were observed in the tempered martensite matrix. The volume fraction of carbides in the STD11 specimen was relatively larger than that in the Cr6C9 specimen, which is due to the difference in the volume fraction of the primary carbide. According to the calculated phase fraction in Figure 1, no primary carbide should exist in the Cr6C9 specimen. It is thought that a small amount of the primary carbide was precipitated during solidification in the Cr6C9 steel due to the non-equilibrium reaction and alloy segregation [11]. Figure 3 shows the SEM images of the tempered Cr6C9 and STD11 specimens. Spherical carbide particles with a diameter of less than $0.5 \mu \mathrm{m}$ were observed in the Cr6C9 specimen whereas carbide particles larger than $1 \mu \mathrm{m}$ in diameter were observed in the STD11 specimen. These large carbide particles seem to come from the precipitation of primary $\mathrm{M}_{7} \mathrm{C}_{3}$ carbide in the solidification or austenitization treatment $[13,14]$. This can be inferred from the equilibrium phase fraction for the STD11 steel as shown in Figure 1b. The smaller size and reduced amount of carbides observed in the Cr6C9 specimen resulted from the reduced amounts of $\mathrm{C}$ and $\mathrm{Cr}[1,11]$.
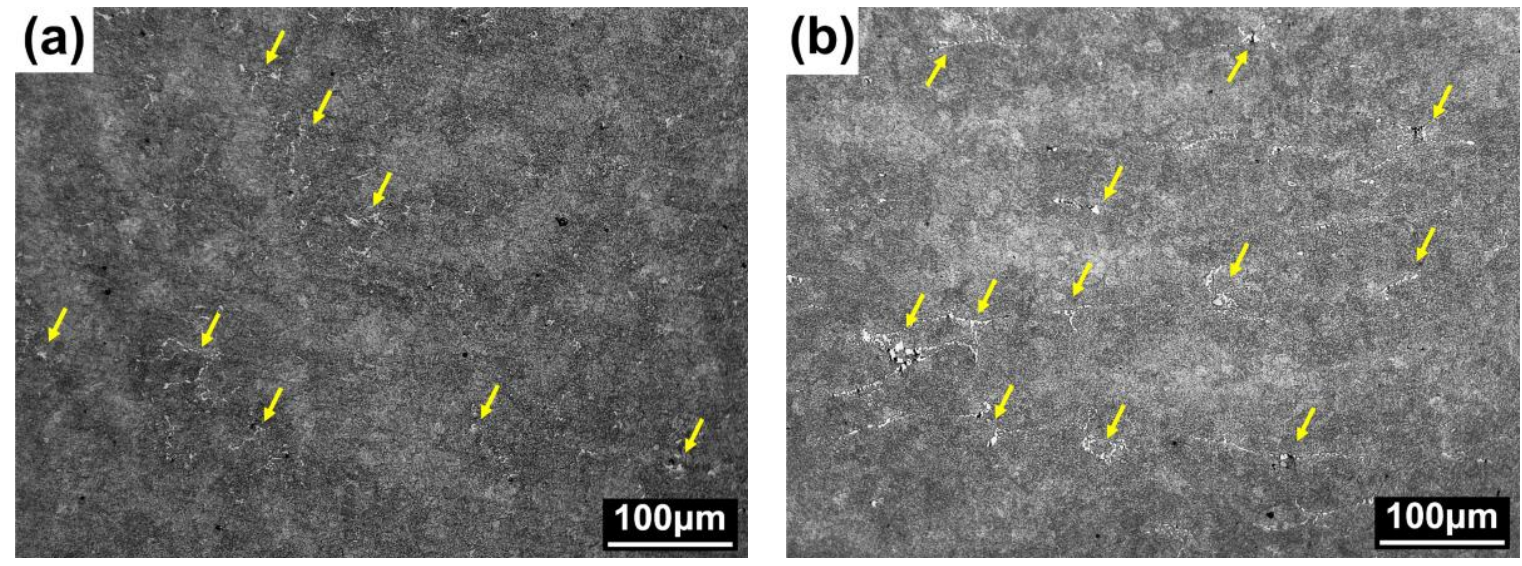

Figure 2. Optical micrographs of the tempered specimens: (a) Cr6C9 and (b) STD11. The arrows indicate the primary carbide in a bright color. 

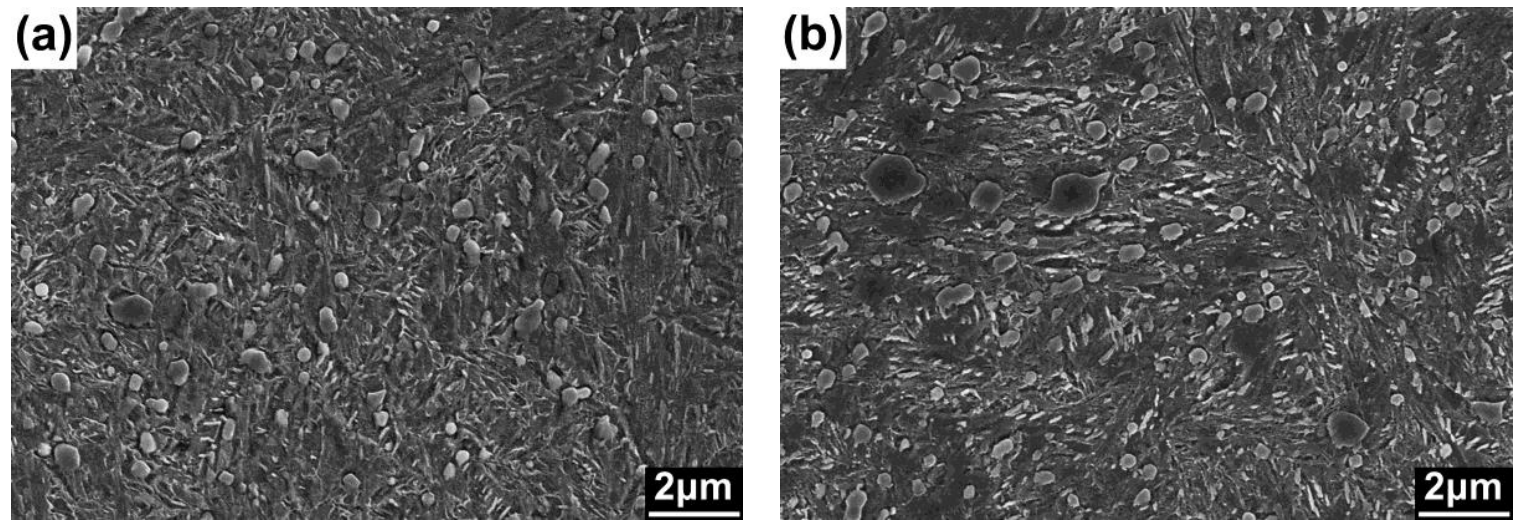

Figure 3. SEM images of the tempered specimens: (a) Cr6C9 and (b) STD11.

The various carbides with different sizes in the tempered Cr6C9 specimen were investigated by TEM analysis and the results are compared to the corresponding result. The selected area electron diffraction (SAED) pattern and EDS result confirmed that coarse carbide particles larger than $200 \mathrm{~nm}$ in diameter had a high $\mathrm{Cr}$ level and a trigonal crystal structure, as shown in Figure 4a. It is reported that the $\mathrm{M}_{7} \mathrm{C}_{3}$ carbide has enriched $\mathrm{Cr}$ content with a trigonal crystal structure [3,15]. This carbide is considered as a $\mathrm{M}_{7} \mathrm{C}_{3}$ precipitate. This is typically precipitated during solidification and is relatively more coarsened compared with other carbides; thus, it is hard to fully dissolve in a high-temperature heat treatment. The chemical composition in the $\mathrm{M}_{7} \mathrm{C}_{3}$ carbide at $520{ }^{\circ} \mathrm{C}$ predicted using MatCalc calculations is 9.8 at. $\% \mathrm{Fe}-53.5$ at. $\% \mathrm{Cr}-2.9$ at. $\% \mathrm{Mn}-1.1$ at. $\% \mathrm{Mo}-2.4$ at. $\% \mathrm{~V}-0.3$ at. $\% \mathrm{~W}-30$ at. $\% \mathrm{C}$. Figure $4 \mathrm{~b}$ shows a carbide particle with a diameter of about $100 \mathrm{~nm}$, containing high Mo and W contents with a face-centered cubic (FCC) crystal structure confirmed by the SAED pattern and EDS result. This precipitate is considered as the $\mathrm{M}_{6} \mathrm{C}$ carbide [3]. The chemical composition in the $\mathrm{M}_{6} \mathrm{C}$ carbide at $520{ }^{\circ} \mathrm{C}$ predicted using MatCalc calculations is 29.5 at. $\% \mathrm{Fe}-37.7$ at. $\% \mathrm{Mo}-13.2$ at. $\% \mathrm{~W}-3.0$ at. $\% \mathrm{Cr}-2.2$ at. $\% \mathrm{~V}-0.1$ at. $\% \mathrm{Si}-14.3$ at. $\% \mathrm{C}$. The $\mathrm{M}_{23} \mathrm{C}_{6}$ carbide also has a FCC crystal structure, but it has a very high $\mathrm{Cr}$ content. The chemical composition in the $\mathrm{M}_{23} \mathrm{C}_{6}$ carbide at $520{ }^{\circ} \mathrm{C}$ predicted using MatCalc calculations is 24.8 at. $\% \mathrm{Fe}-44.3$ at. $\% \mathrm{Cr}-9.8$ at. $\% \mathrm{Mo}-0.4$ at. $\% \mathrm{Mn}-0.7$ at. $\% \mathrm{C}$. A small carbide particle with a diameter of less than $50 \mathrm{~nm}$ is shown in Figure 4c. The SAED pattern confirms the FCC crystal structure and the EDS result indicates a high concentration of Mo and V, but Cr was undetected. This carbide particle is considered as $(\mathrm{Mo}, \mathrm{V}) \mathrm{C}$, not $\mathrm{M}_{23} \mathrm{C}_{6}$, because it is reported that $\mathrm{M}_{23} \mathrm{C}_{6}$ contains the enriched $\mathrm{Cr}[8,16]$ and the MatCalc calculation also shows enriched $\mathrm{Cr}$ in the $\mathrm{M}_{23} \mathrm{C}_{6}$. The equilibrium chemical composition in the $(\mathrm{Mo}, \mathrm{V}) \mathrm{C}$ carbide at $520{ }^{\circ} \mathrm{C}$ predicted using MatCalc calculations is 36.1 at. $\% \mathrm{~V}-15.0$ at. $\% \mathrm{~V}-2.3$ at. $\% \mathrm{~W}-46.6$ at. $\% \mathrm{C}$. It is thought that carbides with a diameter of less than $100 \mathrm{~nm}$, as observed in Figure $4 \mathrm{~b}, \mathrm{c}$, are the secondary carbides precipitated during tempering at a high temperature of $520^{\circ} \mathrm{C}$. These fine carbide particles consist of high concentrations of Mo, $\mathrm{V}$, and $\mathrm{W}$, which could contribute to the improvement of strength and hardness.

Figure 5 compares the mechanical properties of the tempered $\mathrm{Cr} 6 \mathrm{C} 9$ and STD11 specimens. The Cr6C9 specimen indicated a higher hardness value due to the higher contents of Mo, $\mathrm{V}$, and $\mathrm{W}$, even though the $\mathrm{C}$ and $\mathrm{Cr}$ contents were decreased. The increase of hardness by forming carbide particles with Mo, $\mathrm{V}$, and $\mathrm{W}$ is well known as the secondary hardening effect. The impact toughness of the $\mathrm{Cr} 6 \mathrm{C} 9$ specimen was two times higher than that of the STD11 specimen. As confirmed by the microstructure images, a higher volume fraction of coarse primary carbides in the STD11 specimen brought about the lower impact toughness value. The Cr6C9 specimen was superior in the tensile properties to the STD11 specimen because of the work-hardening effect related to the fine secondary carbides, which had strong carbide-forming elements such as Mo, V, and W [17]. Also, it is thought that the better elongation of the $\mathrm{Cr} 6 \mathrm{C} 9$ specimen results from the suppressed formation of the primary carbide. The measured volume fraction of retained austenite determined by XRD analysis for both 
the tempered Cr6C9 and STD11 specimens before deformation was less than 2 vol. \% since the tempering temperature of $520^{\circ} \mathrm{C}$ was high enough to decompose the retained austenite into ferrite and cementite $[6,8,9]$. Thus, the effect of the retained austenite on the mechanical properties is negligible depending on the steel alloy composition.
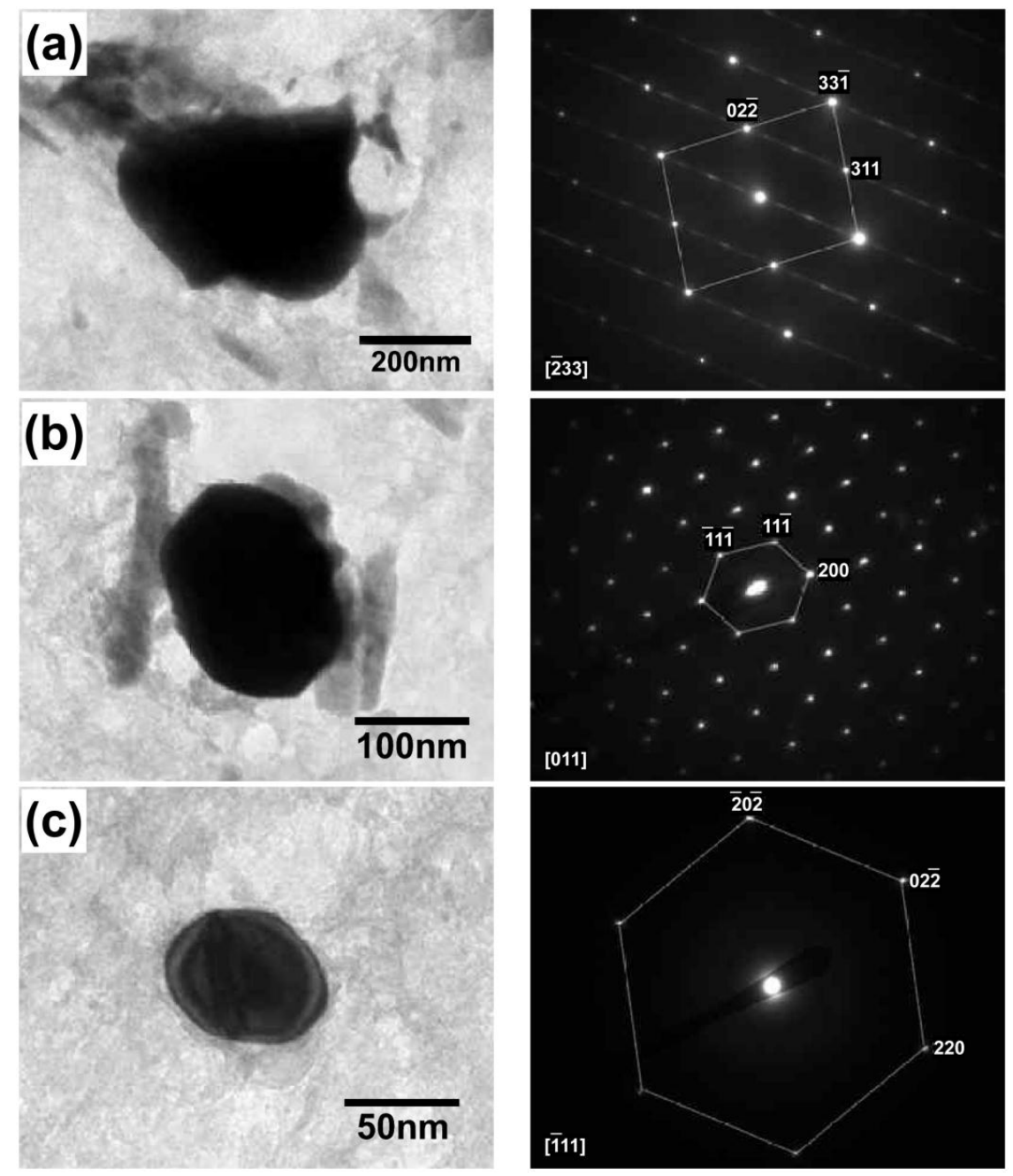

Figure 4. TEM images and the corresponding selected area electron diffraction (SAED) patterns for (a) $\mathrm{M}_{7} \mathrm{C}_{3}$ precipitate; (b) $\mathrm{M}_{6} \mathrm{C}$ precipitate; and (c) $(\mathrm{Mo}, \mathrm{V}) \mathrm{C}$ precipitate.
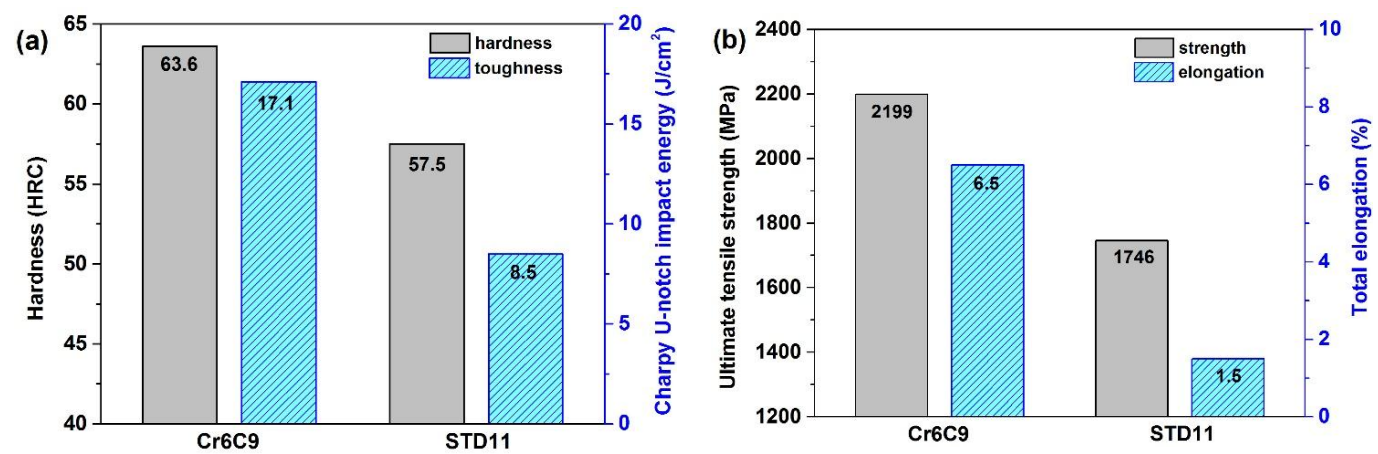

Figure 5. Comparison of the mechanical properties of the Cr6C9 and STD11 specimens: (a) hardness; impact toughness; and (b) tensile properties (ultimate tensile strength and total elongation). 
Figure 6 shows the SEM image of the fracture surface of the Charpy impact testing specimen. The fine carbide was observed at the fracture surface in the $\mathrm{Cr} 6 \mathrm{C} 9$ specimen whereas the coarse carbide was observed at the fracture surface in the STD11 specimen. It is reported that the crack can easily initiate and propagate near coarse carbide, resulting in fracture, as the stress is applied [18,19]. Hence, the lower impact toughness value was caused by the coarse carbide in the tempered STD11 specimen.
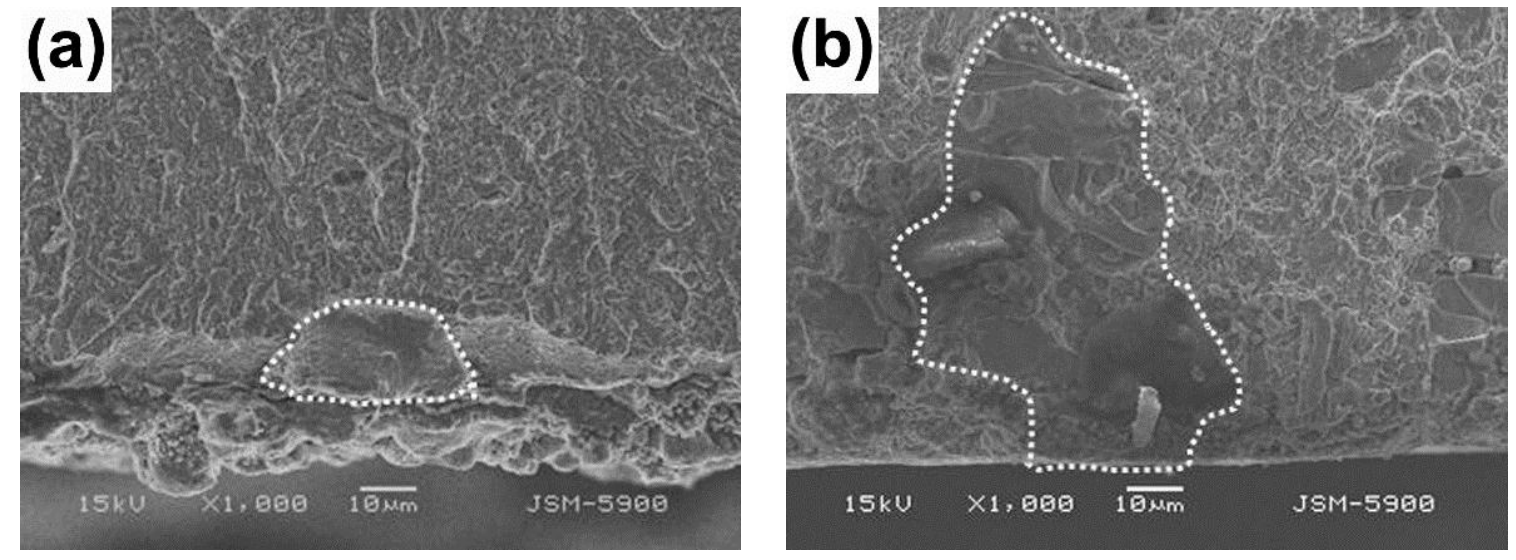

Figure 6. SEM images of fracture surface of the specimens after the Charpy impact test: (a) Cr6C9 and (b) STD11.

\section{Conclusions}

A new cold-work tool steel with a reduced Cr content of $6 \mathrm{wt}$. \% has been developed. The alloy composition of the Cr6C9 steel was designed based on thermodynamic calculation in order to avoid the formation of primary carbide as much as possible during solidification. Even though the primary carbide was observed in both the Cr6C9 and STD11 steels, the Cr6C9 steel showed a smaller carbide particle size and a smaller volume fraction of carbides. The tempered Cr6C 9 steel showed superior mechanical properties compared to the tempered STD11 steel. The higher values of hardness, impact toughness, tensile strength, and total elongation were the result of the fine secondary carbides' precipitation during tempering due to the higher contents of $\mathrm{Mo}, \mathrm{V}$, and $\mathrm{W}$. From the TEM analysis and the thermodynamic calculation, it is considered that $\mathrm{M}_{6} \mathrm{C}$ and $(\mathrm{Mo}, \mathrm{V}) \mathrm{C}$ carbides with a diameter below $100 \mathrm{~nm}$ contributed to the improved mechanical properties of the tempered Cr6C9 steel.

Acknowledgments: This work (Grant No. 1503002010) was supported by the Business for Academic-industrial Cooperative establishments funded Korea Small and Medium Business Administration in 2015. S.-J.L. appreciates the support by the Ministry of Education through the "Leaders in INdustry-university Cooperation" project.

Author Contributions: Seok-Jae Lee conceived and designed the experiments; Minwook Kim performed the experiments; Singon Kang and Seok-Jae Lee analyzed the data; Singon Kang, Minwook Kim and Seok-Jae Lee contributed reagents/materials/analysis tools; Singon Kang and Seok-Jae Lee wrote the paper.

Conflicts of Interest: The authors declare no conflict of interest.

\section{References}

1. Roberts, G.; Krauss, G.; Kennedy, R. Tool Steel, 5th ed.; ASM International: Materials Park, OH, USA, 1998; pp. 7-28.

2. Totten, G.E. Steel Heat Treatment: Metallurgy and Technologies, 2nd ed.; CRC Taylor \& Francis: New York, NY, USA, 2006; pp. 651-694.

3. Krauss, G. Steels: Processing, Structure, and Performance; ASM International: Materials Park, OH, USA, 2005; pp. 535-559.

4. Lee, S.; Kim, S.; Hwang, B.; Lee, B.S.; Lee, C.G. Effect of carbide distribution on the fracture toughness in the transition temperature region of an SA 508 steel. Acta Mater. 2002, 50, 4755-4762. [CrossRef] 
5. Casellas, D.; Caro, J.; Molas, S.; Prado, J.M.; Valls, I. Fracture toughness of carbides in tool steels evaluated by nanoindentation. Acta Mater. 2007, 55, 4277-4286. [CrossRef]

6. Hong, K.J.; Kang, W.K.; Song, J.H.; Jung, I.S.; Lee, K.A. Study on the anisotropic size change by austenitizing and tempering heat treatment of STD11 tool steel using dilatometry. Korean J. Met. Mater. 2008, 46, 800-808.

7. Fukaura, K.; Yokoyama, Y.; Yokoi, D.; Tsujii, N.; Ono, K. Fatigue of cold-work tool steels: Effect of heat treatment and carbide morphology on fatigue crack formation, life, and fracture surface observations. Metall. Mater. Trans. A 2004, 35, 1289-1300. [CrossRef]

8. Kokosza, A.; Pacyna, J. Ewaluation of retained austenite stability in heat treated cold work tool steel. J. Mater. Proc. Technol. 2005, 162-163, 327-331. [CrossRef]

9. Yaso, M.; Morito, S.; Ohba, T.; Kubota, K. Microstructure of martensite in Fe-C-Cr steel. Mater. Sci. Eng. A 2008, 481-482, 770-773. [CrossRef]

10. Kang, J.Y.; Heo, Y.U.; Kim, H.Y.; Suh, D.W.; Son, D.M.; Lee, D.H.; Lee, T.H. Effect of copper addition on the characteristics of high-carbon and high-chromium steels. Mater. Sci. Eng. A 2014, 614, 36-44. [CrossRef]

11. Kim, H.Y.; Kang, J.Y.; Son, D.M.; Lee, D.S.; Lee, T.H.; Jeong, W.C.; Cho, K.M. Microstructure and mechanical properties of cold-wok tool steels: A comparison of $8 \% \mathrm{Cr}$ steel with STD11. J. Korean Soc. Heat Treat. 2014, 27, 242-252. [CrossRef]

12. MatCalc Software. Available online: http://www.matcalc.at (accessed on 31 December 2016).

13. Hwang, K.C.; Lee, S.H.; Lee, H.C. Effects of alloying elements on microstructure and fracture properties of cast high speed steel rolls: Part I: Microstructural analysis. Mater. Sci. Eng. A 1998, 254, 282-295. [CrossRef]

14. Hong, K.J.; Song, J.H.; Chung, I.S. Carbide behavior in STD11 tool steel during heat treatment. J. Korean Soc. Heat Treat. 2011, 24, 262-270.

15. Shim, J.J.; Kim, Y.H.; Lee, S.Y. A study on the growth characteristics of complex carbides precipitated during spheroidizing in medium chromium steels. Korean J. Met. Mater. 1990, 28, 409-415.

16. Yamasaki, S. Modelling Precipitation of Carbides in Martensitic Steels. Ph.D. Thesis, University of Cambridge, Cambridge, UK, 2004.

17. Dieter, G.E. Mechanical Metallurgy, 3rd ed.; McGraw-Hill: New York, NY, USA, 1990; pp. 95-104.

18. Fukaura, K.; Yokoyama, Y.; Yokoi, D.; Tsuji, N.; Ono, K. Fatigue of cold work tool steels: Effect of heat treatment and carbide morphology on fatigue crack formation, life and fracture surface observations. Metall. Mater. Trans. A 2004, 35A, 1289-1300. [CrossRef]

19. Kubota, K.; Ohba, T.; Morito, S. Frictional properties of new developed cold work tool steel for high tensile strength steel forming die. Wear 2011, 271, 2884-2889. [CrossRef]

(C) 2017 by the authors; licensee MDPI, Basel, Switzerland. This article is an open access article distributed under the terms and conditions of the Creative Commons Attribution (CC-BY) license (http:/ / creativecommons.org/licenses/by/4.0/). 